\title{
ENHANCING SEISMIC REGULATORY COMPLIANCE PRACTICES FOR NON-STRUCTURAL ELEMENTS IN NEW ZEALAND
}

\author{
Temitope Egbelakin ${ }^{1}$, Itohan E. Yakubu² and Justin Bowden ${ }^{3}$
}

(Submitted January 2017; Reviewed May 2017; Accepted October 2017)

\begin{abstract}
Most non-structural elements (NSEs) including ceilings, piping, services equipment and cladding systems, etc., are typically prone to failure in the event of relatively low to medium earthquake shakings. The poor performance of NSEs demonstrated in recent earthquake events in New Zealand has revealed a gap in NSE design and construction practices, especially regarding compliance with the NSE performance standard (NZS 4219:2009). This study sought to examine the NZ 4219:2009 and compliance in New Zealand's construction industry, towards improving the performance of NSEs during earthquakes.

Using a face-to-face interview enquiry technique, findings from this study revealed that although majority of the participants consider the NZS 4219:2009 to be very important in improving the performance of NSEs during earthquakes, some shortcomings were also identified: (i) non-compliance with the NZ 4219:2009 by construction professionals; (ii) exclusion of guidelines for specific NSEs from the scope of the NZS 4219:2009; (iii) poor ease of use of the NZS 4219:2009 and other relevant excluded NSE guidelines; and (iv) lack of clarity in the NZS 4219:2009 regarding attribution of ultimate design responsibility for NSE seismic coordination.

As a recommendation, the establishment of a robust, simple-to-use seismic specification document that will provide one-stop specifications for the design and installation of NSEs could be a possible solution to promoting strong compliance practices within the New Zealand construction industry, towards achieving improved performance of NSEs during earthquakes.
\end{abstract}

\section{INTRODUCTION}

The synergy between the seismic performance levels of structural and non-structural elements (NSEs) is of utmost importance to the construction industry due to the advancement and application of performance-based seismic engineering. NSEs are components within a building, not considered as part of the building's primary or secondary structure. NSEs include ceilings, cladding systems, interior partitions, mechanical, electrical, fire protection and plumbing systems, etcetera. NSEs also include contents of a building that are required to aid critical services immediately after a seismic event, such as in a hospital or fire station [1]. Although the immediate or continuous functional performance levels of structural elements in some building could be achieved after an earthquake occurrence, the failure of NSEs may reduce the entire building's performance level [2]. Moreover, NSEs are known to be vulnerable to earthquakes as a result of their instability under dynamic loadings [3, 4], and also when adequate bracing elements and anchorage are not provided for them [1].

Damage to NSEs and building contents during earthquakes could interfere with the functionality and immediate occupancy of critical facilities [1]. This kind of situation have been demonstrated in the 2006 Hawaii earthquake [5], the $2001 \mathrm{El}$ Salvador earthquake [6], and the 1994 Northridge earthquake [7], in North America, where NSEs posed safety hazards to the occupants of hospitals after the earthquakes [2]. Furthermore, the impacts of NSE failure during seismic events could lead to the following catastrophic impacts such as: fire resulting from electrical equipment failure; flooding resulting from ruptured pipework, and building productivity loss as a result of lack of habitation of the building after a disaster [8]. Accordingly, the design and construction of NSEs should ensure that these elements maintain the safety of building occupants during earthquakes.

Over the past decade, the repair and restoration costs of NSEs after seismic events have often exceeded that of major structural framing systems [9]. A contributing factor is that NSEs are usually damaged at lower seismic intensities when compared to structural elements, hence causing significant investment losses from earthquakes $[9,10,12-13]$. From an economic perspective, since NSEs typically account for a majority of building capital costs, damage to these elements during earthquakes will significantly affect the overall building investment costs [14]. NSEs in different building types such as hospitals, hotels and office buildings usually represent about 80-90 per cent of the overall capital investment likely to be damaged in an earthquake disaster [11]. Accordingly, losses from major past seismic events in the United States have been reported to arise from damage to NSEs, which exceeded that from structural elements in the affected buildings [2]. Similarly, in New Zealand, a significant proportion of the estimated 16 billion NZD loss from the the 2010/2011 Canterbury earthquake and aftershock events was attributed to NSEs [15]. The Insurance Council of New Zealand (ICNZ) have also confirmed that the earthquake commission (EQC) and private insurers, paid out this estimated amount for the settling of residential and commercial claims relating to NSEs and building contents since the Canterbury earthquakes [16]

Consequently, the damage of NSEs in seismic events with smaller magnitudes have contributed to majority of these elements remaining vulnerable to seismic hazards $[1,3,12,13,17]$. As buildings are becoming more complex, with

\footnotetext{
1 Senior Lecturer, School of Engineering and Advanced Technology, Massey University, Auckland, T.egbelakin@massey.ac.nz

2 Corresponding Author, PhD Student, School of Engineering and Advanced Technology, Massey University, Auckland, I.yakubu@massey.ac.nz

3 The Fletcher Construction Company Ltd, New Zealand, justinb@fcc.co.nz
} 
architectural finishes and building services systems becoming more extensive and sophisticated, NSEs and building contents are now being generally considered larger components of a property's value [18]. Due to the significant economic impact of NSE damage on business productivity and post-disaster recovery, the improved performance of NSEs in existing buildings should be considered a key issue in most earthquake mitigation initiatives. Moreover, the significance of NSE performance in buildings during earthquakes has resulted in the development of guidelines/standards in countries like the United States [19] and New Zealand [20], which provide current non-structural design provisions based on testing and observations from previous seismic events. However, the major concerns with the poor performance of NSEs during earthquakes appear to be driven by the secondary position of compliance within the construction industry, hence making building information modelling (BIM) for seismic mitigation to be difficult [21]. The NZS 4219:2009 is New Zealand's guideline for NSE detailing, developed to provide improved seismic resilience to NSEs during earthquakes [20]. So far, evidences from the nature of damage and losses to NSEs and restraints from recent seismic events in New Zealand suggest that the lack of implementation of some of the provisions in the existing NZS 4219:2009 has not resulted in a satisfactory outcome [16]. As well, the impacts of non-compliance with the NZS 4219:2009 could negatively affect the load-bearing capacity of NSEs in buildings during seismic occurrences [10, 12].

According to Egbelakin et al. [22], the minimum requirement of life safety in many regulatory provisions is only intended to ensure public health and safety in an earthquake event and in most cases could result in significant economic costs for the repair and restoration of damage to the buildings. Although the NZS 1170.5:2016 amendments will tend to reduce NSE damage by applying serviceable limit state (SLS) 2 to all buildings, there is a need for studies that seek to understand ways on improving the seismic performance of NSEs during earthquakes. This study sought to examine the adequacy of the NZ 4219:2009 in New Zealand's construction industry, for the improved performance of NSEs during earthquakes. Specifically, the objective of this study is to investigate how New Zealand construction professionals view the use and efficacy of the existing NZS 4219:2009. Findings from this study will boost public awareness on improving the compliance culture with the NZS 4219:2009 within New Zealand's construction industry, for the best performance of NSEs during earthquakes.

\section{NEW ZEALAND BUILDING REGULATORY FRAMEWORK DEVELOPMENT}

A combination of building regulations and legislation forms a total performance system for buildings in New Zealand. While the Building act 2004 specifies the legislative framework that governs the overall building works in New Zealand, the building code specifies the minimum performance requirements that all new building works must satisfy (e.g., requirements for fire safety, stability, user safety, energy efficiency, services and facilities, and access) [23]. Building regulations on the other hand provides detail for specific building controls such as prescribed forms, fees and infringements, levies, definitions of 'moderate earthquake' and 'change of use' [23]. Figure 1 depicts the regulatory and performance framework for buildings in New Zealand.
Source: MBIE (2016)

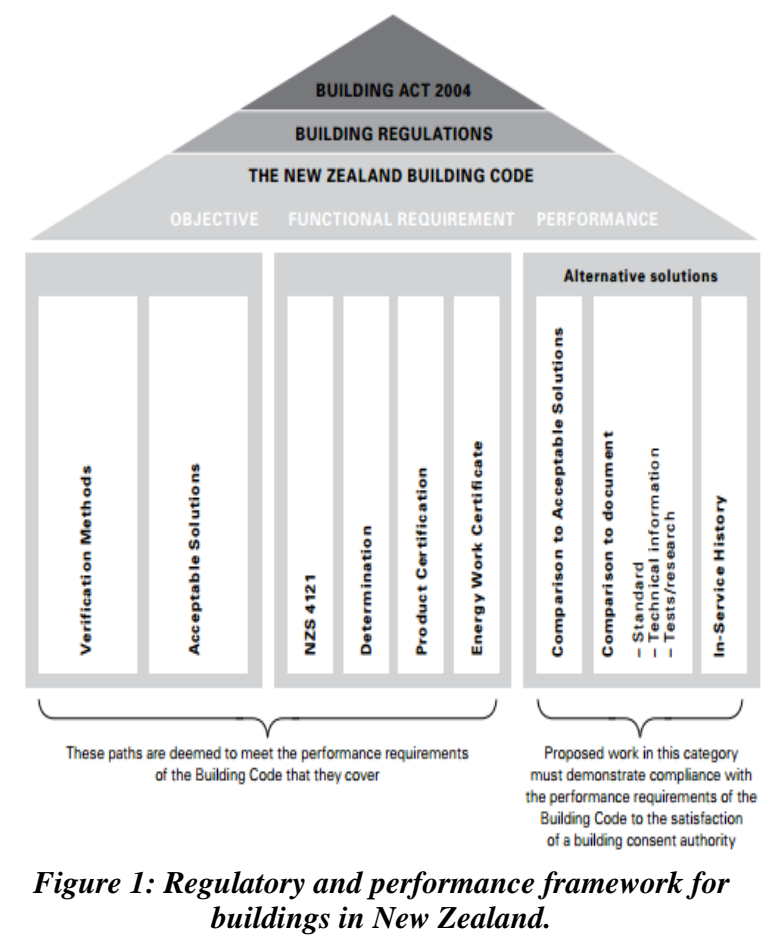

\section{SEISMIC PERFORMANCE OF ENGINEERING SYSTEMS IN BUILDINGS (NZS 4219:2009)}

The NZS 4219:2009 is New Zealand's seismic performance specification for NSEs other than engineering systems covered by NZS 1170.5, developed to replace the specifications for seismic resistance of engineering systems in buildings (NZS 4219:1983). The focus of establishing the NZS 4219:2009 was to ensure that all NSEs in buildings are well restrained during earthquakes [20]. The scope of the NZS 4219:2009 covers the design, construction and installation aspects of NSE seismic restraints, for the improved performance of all components during seismic actions [20]. The components covered include: (i) all engineering systems essential for buildings to function normally, and (ii) all systems required to guarantee compliance with the building standard, and building compliance schedule items (e.g., emergency lighting) [20].

However, the scope of NZS 4219: 2009 does not cover some engineering systems, because they alter the dynamic characteristics of the building. The specifications for their design and installation are already provided for within their respective specific standards (e.g., NZS 4541:2013, AS/NZS 2785, and NZS 4332:1997) [20]. These excluded systems include the pipework of fire sprinkler systems, suspended ceilings, cladding, partitions, lift and escalator systems, building contents (e.g., portable appliances) and other items not fixed to buildings [20]. Additional systems not covered by NZS 4219:2009 include engineering systems in building structures of importance level 5 (IL5), as provided in the NZS 1170.5, and individual components with a mass higher than $20 \%$ of the joint component and building mass [20].

\section{Performance Requirements of the NZS 4219:2009}

The performance requirements and general objectives specified in the NZS 4219:2009 for NSEs require all components to be classified by the designer, based on their expected performance under seismic action. The performance requirements of NSEs are therefore classified under the following categories [20], to meet the criteria of not collapsing, rupturing, or losing support after a seismic event: 
- components that represent a hazard after an ultimate limit state (ULS) earthquake

- components that are required for emergency evacuation (e.g., fire suppression) after an ULS earthquake

- components essential for functional continuity, and restrained in a manner in which their functionality is not restricted after a serviceability limit state (SLS) 2 earthquake (e.g., NSEs of hospitals)

- components restrained in a manner in which their operational and structural integrity is retained without need for repair after a SLS 1 earthquake.

Nevertheless, the above categories are now being classified as part categories, as the latest classifications have been provided in the NZS 1170.5:2016 amendments.

\section{Design and Installation of NSEs According to NZS 4219:2009}

In the existing NZS 4219:2009, two pathways (i.e., specific and non-specific design processes) have been provided for in the design and installation of NSEs, in order to achieve seismic resilience. The provisions of both pathways are specified under sections one to five, and appendices $\mathrm{A}$ to $\mathrm{C}$ of the NZS 4219:2009 [20]. These processes are discussed below:

\section{Non-specific Design Process}

The non-specific design process involves the use of verified proprietary solutions that provide a means of compliance with the building code, to detail NSEs and their connections [20, 2425]. These solutions could be from prescriptive literature developed by technical groups, regulatory standards, or acceptable solutions. There is usually limited non-specific design advice when using this design pathway. Instances where the non-specific design process is applied include fixings such as the detailing of typical light installation, cable tray bracing, duct bracing, bracing of fan coil units, and floor-mounted items [20]. Mechanical and electrical systems are generally required to undergo seismic bracing in accordance with NZS 4219:2009, and ceiling systems according to NZS 1170.5.

According to Shelton [25], many ready-made engineering components are often standard parts of a system, and not originally designed to address specific seismic criteria. Some of these NSEs are often selected by design professionals based on aesthetic considerations or non-structural functionality, thereby neglecting the consideration of seismic performance [26]. Moreover, a majority of these components could have been manufactured in regions of high seismic activity, or in other countries where earthquake-loading standards are not being considered. Although it is acknowledged that these ready-made items are robustly designed to resist significant earthquake shaking, they still need to be seismically verified.

\section{Specific Design Process}

The specific design process permits competent structural engineers to apply structural engineering calculation and rationale in establishing seismic and gravity loads, and the detailing of components for these loads [20, 24-25]. The detailing of components is usually carried out based on the relevant standards for the materials, and the AS/NZS 1170 loading standards. The specific design process requires the verification of design loads for a full range of NSE performance criteria, and cataloguing the results [26]. The AS/NZS 1170.5:2004 [27] for example, has been drafted for the specific purpose of clarifying the ULS or SLS design requirements of all parts and components of suspended ceilings, and the life safety risk interpretations of their individual mass and fall heights.
Instances where the NZS 4219:2009 stipulates the specific design process include components that (i) weigh above $25 \mathrm{~kg}$, (ii) are mounted on walls, (iii) are mounted on floors without an identified centre of gravity, (iv) are brittle, (v) are with intersecting seismic gaps, (vi) are without connections or flexible joints, fitted to building structures of a greater level than one (vii) include gas and steam piping, and (viii) include pipes with a diameter greater than $200 \mathrm{~mm}$ [20].

\section{Current Design and Construction Practices of NSEs in New Zealand}

In the past construction professionals focused on the design requirements of structural systems in building projects, while disregarding the design of NSE restraint systems [12]. For instance, it was typical for structural engineers to focus on the main building structure and not NSEs, which are generally proprietary elements fixed to the buildings [12]. While architects focused on cladding, finishes, ceiling and partitions, building services professionals target electrical systems and mechanical services in their designs. Moreover, architectural and building service items have been reported to be most often specified based on performance requirements rather than prescriptive requirements, in design documents [12].

Presently in New Zealand, the main contractor and the subcontractors are typically in charge of designing and installing seismic bracing systems for NSEs [18]. Although it is now becoming a common practice by main contractors to engage seismic specialists, the design process is usually completed by the NSE subcontractor, while the choice of required systems and units are signed off by a chartered structural engineer. According to BRANZ [28], the design of building services that remain resilient against seismic action in New Zealand is considered a specialist design process, because it is usually outside the seismic engineering proficiency of building services engineers. The building services engineer and structural engineers are required to collaborate with a seismic specialist consultant in order to seismically design, inspect, and certify a project [28]. As a recommendation for the seismic design of NSEs, undertaken by seismic specialist consultants, these specialists are required to deliver seismic design submissions, and also a design project producer statement (PS1) [28]. Moreover, in situations where the NSE seismic design is prepared by the building services engineers, the seismic specialist consultants are still required to peer-review the designs, in order to provide a design producer statement (PS2) [28]. Regarding the installation of the NSEs, it is also suggested that the construction contractors provides a construction producer statement (PS3), which will certify the completion of the installation process in accordance with the design of the seismic specialist consultant [28].

In a study reported by Uma and Beattie [1], a coordinated verification process for applying the NZS 4219:2009 standard for a major new hospital project in New Zealand was documented [1]. The processes implemented by the structural engineers were recorded as follows:

- prepare a specification document for the services subcontractors;

- $\quad$ ensure that the design details of the NSE restraint systems are documented by the services subcontractors;

- ensure that the producer statements (PS1 to PS3) are provided by the subcontractors in order to establish achievement of the specification requirements; and

- ensure that the installation process is constantly verified on site.

New Zealand has an existing building specification for bracing NSEs against seismic loadings, however, a significant number 
of construction projects are still carried out without adequate design and installation of restraint systems [12]. Overall, poor performances of NSEs from the recent Canterbury and Kaikōura earthquakes in New Zealand is a wakeup call for examining the efficacy of NZS 4219:2009 in achieving improved seismic resilience for NSEs during future seismic events.

\section{RESEARCH METHOD}

This study examines the adequacy of the existing NZS 4219:2009 in the design and installation of NSEs and restraint systems against seismic action. A qualitative interview method was adopted, using a face-to-face interview approach, to explore the opinions of professionals involved in the design and construction of NSEs. The rationale for using the interview method was to gain an in-depth understanding of the research problem in its natural context [29], that is, by examining a reallife scenario where this regulatory document has been used and applied.

The participants of interest to this study include professionals and consultants involved in the use and application of the NZS4219:2009 during the design and construction of a building, and specifically for NSE and seismic restraint systems. Based on the research objective, a purposeful sampling process was used to select participants for the interviews. According to Maxwell [30], this strategy allows research to be conducted in a particular setting where individuals or events are deliberately selected to provide in-depth information on the research topic. This sampling approach also allows the involvement of research participants experienced in the subject matter [31-33]. Consequently, participants were selected in this study through a purposeful sampling procedure, based on their knowledge and experience regarding the use and application of NZS 4219:2009 for the design of NSEs and seismic restraints.

\section{Data Collection and Analysis}

Twenty-five participants were selected for a face-to face discussion, based on their knowledge of and familiarity with the NZS 4219:2009 standard. The interviews were recorded and transcribed, with participants' consent. To ensure consistency, an interview protocol was used as a guide during the interview process. To ensure data validity, notes were taken to support the interview audio recording. The interview was conducted for sixty minutes approximately. The transcripts were returned to participants for feedback, to ensure the reliability of the data collected. The interview data was analysed using a thematic analysis technique. This process involved identifying themes in the transcript, to extract consistent patterns from the research results. Several themes were extracted from the interview and are presented in the research findings section. A summary of the research participants' characteristics is provided in the following section.

\section{Research Participants}

The profiles of the interview participants are summarised in Table 1. The main interview participants were structural engineers (32\%), building services engineers (24\%) and architects $(20 \%)$. Other participants included fire protection engineers (12\%), quantity surveyors $(8 \%)$, and a project manager $(4 \%)$. A majority of the participants are in a senior management position within their respective organisations. $76 \%$ of the interviewed participants were in the senior management category. Also, $56 \%$ of the participants work in locations of high seismic risk, suggesting that a significant number of the participants are involved in projects located in medium to high seismic regions. The average level of working experience of the participants was 14 years, with a minimum of four years, and a maximum of 24 years. This high average working-experience level of the interview participant indicates the majority of the participants possess significant knowledge of construction practice and the use of NZS 4219:2009.

Table 1: Profile of interview participants.

CATEGORY FREQUENCY \%

\begin{tabular}{lll}
\hline Profession of Participants & & \\
\hline Structural Engineers & 8 & 32 \\
\hline Architects & 5 & 20 \\
\hline Building Services Engineers & 6 & 24 \\
\hline Fire Protection Engineers & 3 & 12 \\
\hline Project Managers & 1 & 4 \\
\hline Quantity Surveyors & 2 & 8 \\
\hline
\end{tabular}

Primary Location of Participants

\begin{tabular}{lll}
\hline Low Seismic Hazard Area & 4 & 16 \\
\hline Medium Seismic Hazard Area & 7 & 28 \\
\hline High Seismic Hazard Area & 14 & 56
\end{tabular}

Level of Professional Experience (Years)

\begin{tabular}{lll}
\hline$<3$ & - & - \\
\hline $3-7$ & 3 & 12 \\
\hline $7-10$ & 5 & 20 \\
\hline $10-15$ & 4 & 16 \\
\hline$>15$ & 13 & 52 \\
\hline Gender & & \\
\hline Male & 23 & 92 \\
\hline Female & 2 & 8 \\
\hline
\end{tabular}

\section{FINDINGS}

Findings from this study highlight the perspectives of construction professionals regarding the use and efficacy of the existing NZS 4219:2009, during the design and construction of NSEs and restraints systems. These findings are discussed in the following subsections.

\section{Compliance with the NZS4219:2009 for Best Seismic Performance of NSEs}

This study clearly established the importance of compliance with the existing NZS 4219:2009, in improving the seismic resilience of NSEs and restraint systems during earthquakes. $89 \%$ of the participants strongly agreed that compliance was an important factor that would contribute to an improved seismic performance of NSEs. Some of the interview responses include:

"Compliance is very important, especially if strictly enforced for critical facilities"

"Compliance is important if we need to reduce the damage from the smallest earthquake shaking".

Several assertions similar to the above statements, noted during the interview, emphasised the importance of seismic compliance with the building code. On the other hand, $74 \%$ of the interviewed participants believed that compliance with the existing NSE seismic design regulations is relatively low or non-existent within New Zealand's construction industry, especially for buildings categorised under importance levels one and two, where a non-specific design pathway is typical for the installation of NSEs. Figure 2 depicts these findings. 


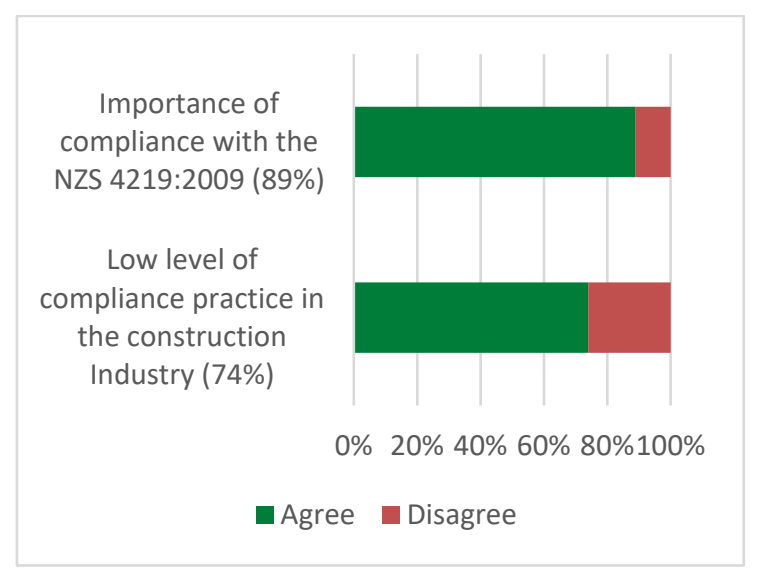

Figure 2: NSE seismic compliance practices in New Zealand construction industry.

\section{Reasons for Non-Compliance with NZS 4219:2009}

A proportion of the interviewed participants explained that the following factors generally contribute to poor compliance with the NZS 4219:2009 (see Figure 3):

inadequate provision for design fees specifically allocated to the design of NSEs in main design contracts, $(78 \%)$

inadequate seismic education of a significant number of design and construction professionals, manufacturers and contractors, $(81 \%)$

lenient penalties in the regulatory enforcement of compliance $(62 \%)$

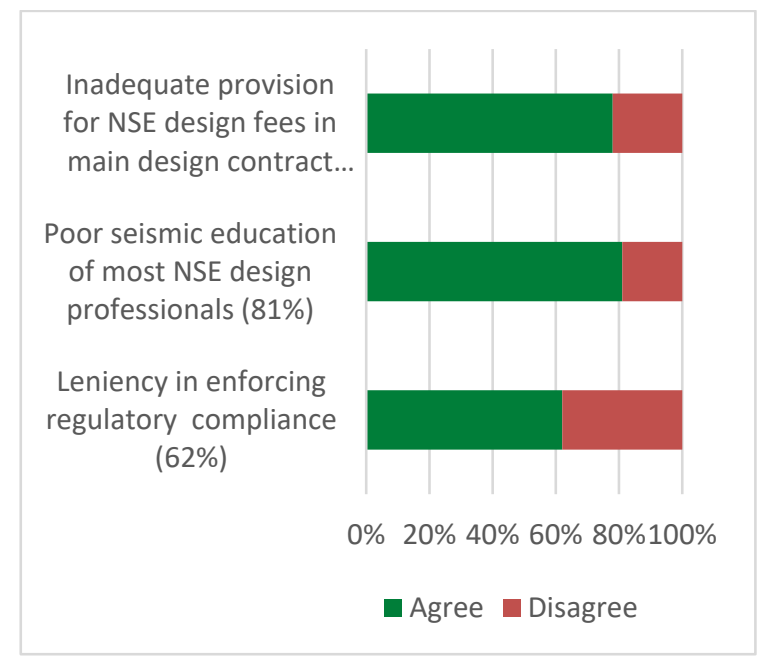

Figure 3: Factors that contribute to non-compliance.

In a similar EERI survey conducted in the United States in 2009 [26], compliance with seismic design regulations for NSEs was considered to be of high importance to the construction industry for acceptable performance of NSEs during earthquakes. Accordingly, the following significant reasons were identified for non-compliance in the EERI survey [26]: inadequate training for NSE seismic facilitators; minimal enforcement of compliance with the regulatory standards; and uncertainty regarding who should be responsible for compliance. The associated benefits of addressing the above concerns regarding best seismic performance of NSEs were also highlighted in the survey [26]
Exclusion of Guidelines for Specific NSEs from the Scope of the NZS 4219:2009

Majority (79\%) of the interviewed participants believed that the exclusion of guidelines for some particular NSEs from the scope of the NZS 4219:2009 has made the monitoring process for adequate detailing of NSE restraints tedious. Section 1.1.2 of the NZS 4219:2009 specifically excludes some NSEs from its scope because they are already provided for in their specific standards, such as; AS/NZS 1170.0, NZS 4541:2013, AS/NZS 2785, and NZS 4332:1997. These excluded items include: (i) Engineering systems in buildings of importance level 5, as defined in AS/NZ 1170.0, (ii) individual components with a mass exceeding $20 \%$ of the combined mass of the component and the structure, and with a tremor period of greater than 0.2 seconds, (iii) items supported on the ground independently of the building, and external to the building, (iv) lifts (including guide rails) and escalators, (v) contents of the buildings including portable appliances, and items which are not attached to the building structure, (vi) fire-sprinkler system pipework, and (vii) suspended ceilings.

These separate specification documents make it difficult for adequate regulatory enforcement, through checks and monitoring during the design and consent approval processes. During the construction phase, some NSEs and bracing systems that are not well designed or fully specified, often leading to compromises in the choice of system installed. Consequently, strict compliance is not adhered to due to subcontractors of these separately specified NSEs assuming that other parties will ensure seismic compliance. Some of the interview participants mentioned that over the years, the industry has flooded the market with several NSE products from countries with different seismic regulations, and their performance may or may have not been adequately tested to suit New Zealand seismic situations. In addition, the selection of many NSE restraints is often done during the construction phase, which may result in poor design, or no design at all, for best seismic performance.

Ease of Use of NZS 4219:2009 and other Relevant Excluded NSE Guidelines

Findings from this study revealed several difficulties with the use of NZS 4219:2009 during the design and construction process of NSEs. $91 \%$ of the sampled construction professionals strongly believed that it is very difficult to combine various overlapping standards of the excluded NSEs from the NZS 4219:2009, when detailing seismic and gravity loads for the components. Some of the participants explained that:

"The specifications of the existing NSE design documentation need to be harnessed towards more typical and clearer classification of anchored items and their respective seismic design factors"

"The code is too complicated; it's really cumbersome work going through the various requirements of many NSEs in their respective standards during the design stage"

"We just need a one-stop seismic performance specification document for all NSEs"

Moreover, $85 \%$ of the sampled participants believe there exists some form of inconsistency when combining the NZS 4219:2009 \& other guidelines of excluded NSEs. This disparity could be attributed to the requirements and complexity associated with managing and coordinating personnel across several disciplines with different NSE components, including designers, manufacturers, main contractors and subcontractors. Figure 4 portrays these findings. 
Poor ease of use of the NZS 4219:2009 \& other guidelines of excluded NSEs (91\%)

Inconsistency when combining the NZS 4219:2009 \& other guidelines of excluded...

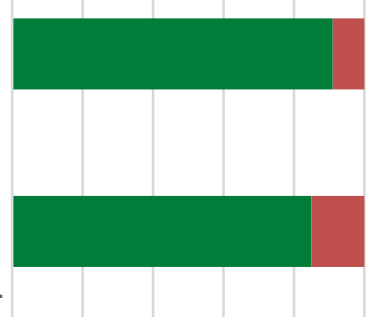

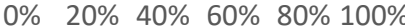

- Agree Disagree

Figure 4: Ease of use of the NZS 4219:2009 and other excluded NSE guidelines.

\section{Lack of Clarity in NZS 4219:2009 Regarding Attribution of Ultimate Design Responsibility for NSE}

The last paragraph of Section 4.3 of NZS 4219:2009 reads; "in the absence of appropriate material standards, the designer shall be responsible for specifying relevant material properties which are consistent with a limit state design philosophy" [20]. 73\% of the interviewed participants believe that the existing NZS 4219:2009 lacks clarity in specifically defining the construction professional who would be ultimately responsible for the role of NSE seismic design and construction processes, when using the non-specific design approach. The implementation of this section of the NZS 4219:2009 has led to lack of clarity in the attribution of responsibility for the design of NSEs and restraints systems in industry practice. The 2009 EERI report [26] refers to this kind of circumstances as the "diffused responsibility matrix", where no specific group of professionals are assigned the responsibility of ensuring the adequate seismic design and detailing of NSEs.

When the interviewees were asked who the ultimate design of NSEs should be attributed to, $82 \%$ of the participants believed the position should be that of a seismic design coordinator for NSEs. The participants argued that an NSE seismic coordinator is essential in every project team to oversee the design, compliance and monitoring all NSE-related work. Furthermore, $70 \%$ and $30 \%$ of the participants believed the responsibility should be that of the building services consultants, and the main project contractors respectively. Figure 5 depicts these findings.

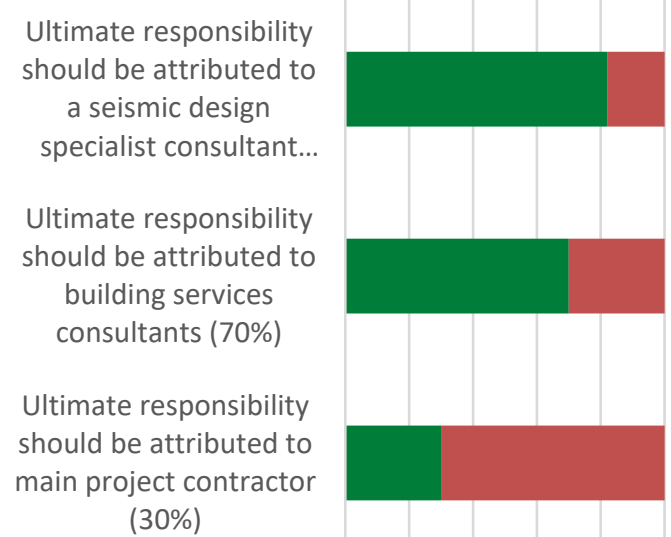

0\% 20\% 40\% 60\% 80\% $100 \%$

- Agree Disagree

Figure 5: Attribution of ultimate design responsibility for NSES.
The current approach in New Zealand seismic engineering practices involves main contractors focussing on structural components only, or the involvement of building service consultants such as fire, mechanical, and electrical components. Often, NSE bracing and restraints systems are excluded from the scope of work of these consultants. With no clear attribution of responsibility for the design of NSEs using the non-specific design approach in the NZS4219:2009 standard, the construction industry is subject to various ambiguities and possible interpretational issues during the design and installation of NSEs.

\section{DISCUSSION AND RECOMMENDATIONS}

The goal of this study was to examine the adequacy of the existing NZ 4219:2009 standard for the design and installation of NSE seismic restraints against seismic activity, from the viewpoints of construction professionals. The research findings revealed that the inadequacy of the standard could be attributed to the following: (i) non-compliance with the NZ 4219:2009 by construction professionals; (ii) exclusion of guidelines for specific NSEs from the scope of the NZS 4219:2009; (iii) poor ease of Use of the NZS 4219:2009 and other relevant excluded NSE guidelines; and (iv) lack of clarity in the NZS 4219:2009 regarding attribution of ultimate design responsibility for NSE seismic coordination. These findings suggest the inadequacy of the NZ 4219:2009 in New Zealand's construction industry, for the improved performance of NSEs during earthquakes.

Although majority of sampled construction professionals viewed the NZS 4219:2009 as very important for enhanced seismic performance of NSEs, their level of compliance with the document was very low. As observed from the economic losses incurred from damage to NSEs during the recent global earthquake swarms [11], the efforts of policy regulators to enforce compliance with the NSE regulatory document has not been very successful. Findings from a similar EERI survey conducted in the United States in 2009 [26] suggests a close overlap with the findings from this study in the areas of compliance, and ultimate design role attribution for NSE seismic design. This overlap suggests that the non-compliance with NSE regulatory documents, and hence poor performance issues of NSEs during earthquakes, are not particular to New Zealand alone. Due to the unreliable levels of compliance with the NZS 4219:2009 in New Zealand's construction industry, and the difficulty in trying to achieve compliance with the document, specific guidelines such as the CCCA for mechanical services [34] and the AWCI for suspended ceilings [35], have been developed for the purpose of improving compliance.

Improving the seismic performance of NSEs to achieve life safety and reduced costs from damage to properties and downtime, depends on the competent coordination of NSEs during the design, procurement and construction stages of a building project [24]. According to the MBIE Practice advisory 19 document [24], the performance of NSEs during earthquakes could be improved through: (i) Critical detailing of restraints, connections, and the identification and documentation of flexible elements; (ii) collaboration between architects and other construction professionals in seeking specialist seismic engineering advice concerning the detailing of fit-outs and restraints; (iii) Timely coordination of NSE systems to avoid conflicting work schedule and specifications; and (iv) construction monitoring. Furthermore, the current New Zealand practice as specified in the recently updated MBIE Building performance document [23], requires building owners, designers and contractors to satisfy the minimum seismic performance requirements before they can be issued a building consent. The building consent authorities are required to accept evidence of building code compliance from the building owners, which could be either acceptable solutions or 
verification methods to demonstrate compliance with the building code. Additionally, the territorial authorities are required by the current building regulatory regime [23] to monitor compliance schedules and follow up notices to fix, issue project information memoranda and certificates of acceptance, and also, infringement notices for non-compliance.

The following recommendations are put forward based on the findings from this study, and the present issues identified with current practices regarding the design, procurement and installation of NSEs, for their improved performance during earthquakes:

- the establishment of a robust, simple-to-use seismic compliance specification document that will provide onestop guidelines for the design and installation of NSEs. This one-stop specification document would promote improved industry compliance practice, towards achieving improved seismic performance of NSEs.

- the existing NZS 4219:2009 should be revised to clearly define the role of a NSE specialist coordinator, who will coordinate the design and installation of NSEs in both newly constructed and retrofitted buildings. Additional responsibility may include certification of new NSEs, and of restraint systems or products. This coordinator would ensure the manufactured items and proprietary NSEs (whether from New Zealand or imported) are able to meet New Zealand's seismic performance conditions. The role of a NSE coordinator should be considered an appropriate approach to be adopted by building owners for future projects. The specialist consultants should also be able to guide relevant construction professionals during the seismic verification and testing of NSEs, restraints and bracing systems.

- $\quad$ onsite construction monitoring of NSE installation by a seismic coordinator will help ensure that seismic design details are installed to meet the seismic performance regulatory requirements, for example, with strict monitoring of the installation of critical seismically designed flexible joints between NSEs, across seismic gaps, and separations between NSEs. The construction monitoring process should be followed by a seismic certification process, where the specialist designer provides a form of certification (i.e., construction producer statement) stating the completion of the work in accordance with seismic compliance with NZS 4219:2009.

- there is also a need for increased seismic education among project team members. Relevant NSE construction professionals and manufacturers should be well educated, through regular workshops and seminars on the seismic performance of NSEs, in order to promote adequate compliance practices within the construction industry.

- provision should also be made for an enhanced regulatory enforcement of the existing NZS 4219:2009, through the implementation of stricter penalties for non-compliance. In other words, projects should only be approved on the basis of compliance, mainly during the consent approval process.

- importantly, all construction professionals should collectively strive for specialist advice regarding the seismic design and installation of NSE seismic restraints, especially in situations where there is no direct involvement of a specialist NSE seismic engineer. Effective collaboration between construction professionals would address any issues relating to conflicting work plans and design specifications procurement difficulties regarding NSEs could be minimised through the provision of a better basis for tendering and costing.
The recommendations of this study could be considered a starting point for more work on improving the clarity in scope and effectiveness of NZS 4219:2009, as perceived by construction professionals.

\section{CONCLUSIONS}

This study examined the opinions of construction professionals regarding the efficacy of NZS 4219:2009 for the design and installation of NSEs, to improve their performance during seismic events. Although the applied enquiry mode for this research may not have been a most viable scientific method for data collection due to time constraint, further research on this topic will explore other enquiry modes. Accordingly, findings from this study revealed that strong compliance with the NZ 4219:2009 by construction professionals is very essential for best performance of NSEs during earthquakes. Most construction professionals understand the full implications of the non-performance of NSE seismic restraints against seismic activity, yet practices to ensure compliance are not being strictly followed. The need for relevant policy regulators in ensuring that the existing NZS 4219:2009 is revised to allow for ease of use, towards promoting compliance was also highlighted. Also, NSE seismic specification documents should be capable of providing users with likely solutions to frequently encountered circumstances relevant to the design and installation of NSEs and restraint systems in New Zealand.

Furthermore, the establishment of a robust, simple-to-use seismic specification document that will provide one-stop specifications for the design and installation of NSEs could be a possible solution to enhance compliance. This one-stop specification document would promote improved industry compliance practice, towards achieving improved seismic performance of NSEs in New Zealand. Findings from this study could be useful to professionals and researchers involved in the investigation of NSE seismic performance.

\section{REFERENCES}

1. Uma S and Beattie G (2010). "Seismic assessment of engineering systems in hospitals - a challenge for operational continuity". Proceedings of the NZSEE Annual Conference, Wellington, Paper No 21.

2. Filiatrault A and Sullivan T (2014). "Performance-based seismic design of nonstructural building components: The next frontier of earthquake engineering". Earthquake Engineering and Engineering Vibration, 13(1): 17-46.

3. Elkink A (2015). Seismic Restraint of Building Services. http://www.buildmagazine.org.nz/articles/show/seismicrestraint-of-building-services (accessed 16/05/2017).

4. Lee TH, Kato M, Matsumiya T, Sugita K and Nakashima M (2007). "Seismic performance evaluation of nonstructural components: drywall partitions". Earthquake Engineering \& Structural Dynamics, 36(3): 367-382.

5. Chock G, Robertson I, Nicholson P, Brandes H, Medley E, Okubo P and Linurna G (2006). "Compilation of Observations of the October 15, 2006 Kiholo Bay (Mw 6.7) and Mahukona ( $M_{w}$ 6.0) Earthquakes, Hawaii”. Earthquake Engineering Research Institute, 31pp.

6. Boroschek R and Retamales R (2001). "Damage Observed in El Salvador's Public Hospital System during the January 13, 2001 Earthquake". WHO/PAHO Collaborating Center for Disaster Mitigation in Health Facilities, University of Chile, Santiago, Chile.

7. McGavin GL and Patrucco HA (1994). "Survey of Nonstructural Damage to Healthcare Facilities by the January 17, 1994 Northridge Earthquake". HMC Group, Ontario, Canada. 
8. Beattie GJ (2000). "The design of building services for earthquake resistance". Proceedings of the of 12th World Conference on Earthquake Engineering, Auckland, NZ.

9. Dhakal RP, MacRae GA and Hogg K (2011). "Performance of ceilings in the February 2011 Christchurch earthquake". Bulletin of the New Zealand Society for Earthquake Engineering, Christchurch Earthquake Special Issue, 43(4): 377-387.

10. Braga F, Manfredi V, Masi A, Salvatori A and Vona M (2011). "Performance of non-structural elements in RC buildings during the L'Aquila, 2009 earthquake". Bulletin of Earthquake Engineering, 9: 307-324.

11. Miranda E, Mosqueda G, Retamales R and Pekcan G (2012). "Performance of nonstructural components during the 27 February 2010 Chile earthquake". Earthquake Spectra, 28(S1): S453-S471.

12. Ferner H, Wemyss M, Baird A, Beer A and Hunter D (2014). "Seismic performance of non-structural elements within buildings". Proceedings of the NZSEE Annual Conference, Auckland, Paper No 69.

13. Perry C, Phipps M and Hortacsu A (2009). Reducing the Risks of Nonstructural Earthquake Damage. http://dx.doi.org/10.1061/41084(364)62 (accessed 17/05/2017).

14. Taghavi S and Miranda E (2003). "Response Assessment of Non-structural Building Elements". Report No. 2003/05. Pacific Earthquake Engineering Research Center, Richmond, CA.

15. Dhakal RP (2010). "Damage to Non-structural Components and Contents in the 2010 Darfield Earthquake". Bulletin of the New Zealand Society for Earthquake Engineering, Darfield Earthquake Special Issue, 43(4): 404-411.

16. ICNZ (2016). Failure to comply with standards a likely cause of Wellington commercial building damage. Media Centre. http://www.icnz.org.nz/category/press-release/ (accessed 17/05/2017).

17. Banks G and Dunbar A (2015). "Seismic design of interior overhead non-structural elements". Proceedings of the NZSEE Annual Conference, Rotorua, Paper No 70.

18. Ferner H, Lander M, Douglas G, Baird A, Wemyss M and Hunter D (2016). "Pragmatic Improvements to Seismic Resilience of Non-Structural Elements -Practitioners Perspective". Bulletin of the New Zealand National Society for Earthquake Engineering, 49(1): 22-33.

19. FEMA (2015). "Reducing the Risks of Nonstructural Earthquake Damage. A Practical Guide - FEMA E-74". Federal Emergency Management Agency. Washington, DC.

20. SNZ (2009). "NZS 4219:2009: Seismic Performance of Engineering Systems in Buildings". Standards New Zealand, Wellington, NZ.

21. Welch DP, Sullivan TJ and Filiatrault A (2014). "Potential of Building Information Modelling for Seismic Risk
Mitigation in Buildings". Bulletin of the New Zealand Society for Earthquake Engineering, 47(4): 253-263.

22. Egbelakin $\mathrm{T}$, Wilkinson $\mathbf{S}$, Potangaroa $\mathbf{R}$ and Ingham $\mathbf{J}$ (2013). "Improving regulatory frameworks for earthquake risk mitigation". Building Research and Information, 41(6): 677-689.

23. MBIE (2016). Building Regulatory Framework: Building Performance. Ministry of Business Innovation \& Employment, Wellington, New Zealand. Retrieved from file:///C:/Users/eyakubu/Downloads/nz-regulatoryframework-2868\%20(2).pdf (accessed 15/05/2017).

24. MBIE (2016). Practice Advisory 19: Improving Earthquake Performance of Non-structural Elements (9780-947524-81-4). Ministry of Business Innovation and Employment, Wellington, New Zealand. Retrieved from https://www.building.govt.nz/assets/_generated_pdfs/pract ice-advisory-19-4189-all.pdf. (accessed 15/05/2017).

25. Shelton RH (2009). Revised Seismic Standard for Building Services. http://www.buildmagazine.org.nz/assets/PDF/B11160ResearchSeismic.pdf (accessed 08/11/2016).

26. Masek J and Ridge R (2009). "Identification of Methods to Achieve Successful Implementation of Nonstructural and Equipment Seismic Restraints". Earthquake Engineering Research Institute, Oakland, CA.

27. SNZ (2016). "NZS 1170.5:2004 - Structural Design Actions Part 5, Earthquake Actions - Amendment 1". Standards New Zealand, Wellington, NZ.

28. BRANZ (2015). Non-Structural Components: Seismic Resilient Non-Structural Element Fact Sheet. Building Research Association of NZ. http://www.branz.co.nz/nonstructural (accessed 17/12/2016).

29. Kvale S (1983). "The qualitative research interview: A phenomenological and a hermeneutical mode of understanding". Journal of phenomenological psychology, 14(2): 171-182.

30. Maxwell JA (2012). “Qualitative Research Design: An Interactive Approach". Sage Publications, London.

31. Babbie ER (2013). "The Basics of Social Research". Sixth Edition, Cengage Learning, Wadsworth, USA.

32. Easterby-Smith M, Thorpe R and Jackson PR (2012). "Management Research". Sage Publications, London.

33. Neuman LW (2014). "Social Research Methods: Qualitative and Quantitative Approaches". Seventh Edition, Pearson Education Limited: Essex, England.

34. CCCA (2014). Seismic Process Guide for Mechanical Services Subcontractors. http://www.irhace.org.nz/uploads/Seismic\%20Process $\% 20$ Guide\%20for\%20Mechanical\%20Services\%20Subcontrac tors\%20October\%202014.pdf (accessed 15/05/2017).

35. AWCINZ (2015). Code of Practice for Design, Installation and Seismic Restraint of Suspended Ceilings. http://awci.org.nz/wp-content/uploads/2011/09/AWCICoP-Web.pdf (accessed 15/05/2017). 